\title{
Análise Computacional de Sistemas Estruturais Não-Lineares
}

\author{
Jéssica V. Cicala, Anderson V. Pires, Luiz C. M. Vieira Junior.
}

\section{Resumo}

Este trabalho tem por objetivo a construção de um método computacional capaz de avaliar a carga máxima de estabilidade de estruturas, levando em conta os efeitos da não linearidade geométrica. A validação do algorítmo construído foi feita por meio de comparação entre os resultados obtidos e valores teóricos.

\section{Palavras-chave:}

Análise não-linear, análise de flambagem, elementos finitos.

\section{Introdução}

A não linearidade em estruturas pode ser dividida em dois grandes campos: a não linearidade física e a não linearidade geométrica. A não linearidade física advém do fato que os materiais utilizados na construção dos elementos não são perfeitamente elásticos. Estendendo o raciocínio, pode-se concluir que a não linearidade física está intimamente relacionada com o comportamento da curva de tensão vs deformação do material utilizado na construção da estrutura.

Diferentemente, a não linearidade geométrica está relacionada ao aumento de esforços internos da estrutura na posição deformada. Isto é, após a aplicação de carregamentos, a estrutura se deforma e os esforços necessários para manter a estrutura em equilíbrio aumentam.

O estudo da não linearidade geométrica, i.e., da posição deformada, é fundamental para analisar a situação de perda de estabilidade de uma estrutura, haja visto que a carga crítica de flambagem é definida como a carga axial que leva a estrutura à posição deformada. Note que à medida que a estrutura deforma, os esforços são alterados, caracterizando, desta forma, um processo iterativo.

Portanto, o objetivo deste trabalho é a construção de um algoritmo capaz de determinar a carga crítica de flambagem levando em conta a não linearidade geométrica da estrutura.

\section{Resultados e Discussão}

Utilizando o algoritmo construído no software MatLab foi possível calcular a carga crítica de instabilidade e, também, plotar a curva de deslocamento em função da solicitação.

Como o vetor de deslocabilidades livres é conhecido, é possível obter a matriz de rigidez referente aos deslocamentos livres da estrutura e a matriz de rigidez referente as deslocabilidades conhecidas, ou seja, as deslocabilidades travas com vinculação e que sendo assim serão nulas.

Utilizando o método de Newton-Raphson calcula-se a posição equilibrada da estrutura. Calculando os autovalores da matriz de rigidez das deslocabilidades desconhecidas, é possível conhecer a carga crítica de flambagem.

Como primeiro teste, foi calculado a carga crítica para uma coluna ideal, mostrada na figura 1. Sabe-se que a carga de crítica desta estrutura corresponde à carga de flambagem de Euler $\left(P=\pi^{2} E I / L^{2}\right)$. Os resultados obtidos no programa em MatLab estão demonstrados na figura
2. A fim de obter a constante $\pi^{2}$ utilizou-se $E=1, I=2, L=1$ e desconsiderando as deformações axiais.

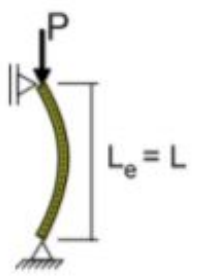

Figura 1: Coluna ideal biarticulada

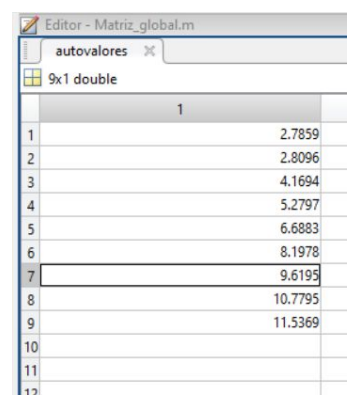

Figura 2. Análise de Buckling realizada pelo MatLab

\section{Conclusões}

Os resultados obtidos no MatLab mostram a convergência dos valores obtidos para a carga crítica da coluna de Euler. Desta forma, pôde-se validar o programa construído.

\section{Agradecimentos}

Agradeço imensamente meu professor orientador Luiz C. M. Vieira Junior por todo o tempo disponibilizado para me ajudar, pela orientação e dedicação.

Agradecimento especial para o Anderson, mestrando que me auxiliou diversas vezes, por toda a paciência e carinho dedicado.

BEER, Ferdnand P.; JOHNSTON JUNIOR, E. Russell. RESISTÊNCIA DOS MATERIAIS. 3. ed. K: Makron Book, 00000. 1255 p.

LOURENÇO, Paulo B.. Métodos computacionais na mecânica dos sólidos nãolinear. 1999. $124 \mathrm{p}$.

RIBEIRO, Iara Souza. Análise não-linear geométrica de sistemas aporticados planos com elementos de rigidez variável - aplicações em estruturas de aço e de concreto armado. 2016. 85 f. Tese (Doutorado) - Curso de Engenharia Civil, Universidade Federal de Ouro Preto, Ouro Preto, 2016.

LOURENÇO, Paulo B.. Métodos computacionais na mecânica dos sólidos não-linear. 128 f-Curso de Engenharia Civil, Universidade do Minho, 1999. 